\title{
Therapeutic Specificities and Prognosis of Advanced Stage and Metastatic Bladder Cancers in a Tunisian University Hospital
}

\author{
Zaied Sonia', Khechine Wiem¹, Bourigua Rim¹, Abbess Ibtissem¹, Ktari Kamel2, \\ Ben Ali Yosri' ${ }^{2}$, Daldoul Amira ${ }^{1}$ \\ ${ }^{1}$ Department of Medical Oncology, Fattouma Bourguiba University Hospital, Monastir, Tunisia \\ ${ }^{2}$ Department of Urology, Fattouma Bourguiba University Hospital, Monastir, Tunisia \\ Email: amira.krir@outlook.com
}

How to cite this paper: Sonia, Z., Wiem, K., Rim, B., Ibtissem, A., Kamel, K., Yosri, B.A. and Amira, D. (2017) Therapeutic Specificities and Prognosis of Advanced Stage and Metastatic Bladder Cancers in a Tunisian University Hospital. Open Access Library Journal, 4: e3894.

https://doi.org/10.4236/oalib.1103894

Received: August 19, 2017

Accepted: October 15, 2017

Published: October 18, 2017

Copyright $\odot 2017$ by author and Open Access Library Inc.

This work is licensed under the Creative Commons Attribution International License (CC BY 4.0).

http://creativecommons.org/licenses/by/4.0/

\begin{abstract}
In Tunisia, bladder cancer represents the first urological cancer before even prostate cancer. However, its diagnosis is often delayed to the stage of invasive tumor. Systemic chemotherapy represents an option for inoperable and/or metastatic forms. Our study's aims were to report our center's therapeutic results for locally advanced and metastatic forms of bladder cancer and to analyze its prognosis factors. In our 40 patients with bladder cancer advanced stages (locally advanced and metastatic), transitional cell carcinoma was the most common histological type (82.5\%); mean age at diagnosis was $63.3 \pm$ 10.5 years with a sex ratio equal to 12.3 ; radical cystectomy and radiation therapy were performed separately both in $35 \%$ of cases and chemotherapy in $60 \%$; cisplatin associated with gemcitabine was the most used regimen and navelbine monotherapy was used as second-line chemotherapy; median overall survival was 14.4 months, and its influencing factors according to our results were: ECOG score, $\mathrm{T}$ and $\mathrm{M}$ tumor stages, primary tumor surgery and adjuvant chemotherapy.
\end{abstract}

\author{
Subject Areas \\ Oncology, Urology \\ Keywords \\ Bladder Neoplasms, Epidemiology, Treatment, Prognosis
}

\section{Introduction}

Bladder cancer is the $9^{\text {th }}$ cancer in the world and accounts for $2 \%$ to $5.5 \%$ of all 
malignant tumors [1]. It represents the $4^{\text {th }}$ rank in the world in terms of incidence in men and $9^{\text {th }}$ in women [2]. More than 330,000 new cases described worldwide and more than 130,000 deaths per year and 2.7 million patients have a history of bladder cancer [2].

In Tunisia, bladder cancer represents the first urological cancer. From 1993 to 2001 its incidence has clearly increased from 14.5 to 21.6 cases/100,000 inhabitants [3]. Its prevalence was $11.7 \%$ in 2001 [4].

The diagnosis is often delayed to a stage of invasive tumor where therapeutic management includes several modalities. Systemic chemotherapy represents a therapeutic option for inoperable and/or metastatic forms.

The aim of our study is to report results of our mono-center survey of five years for locally advanced and metastatic forms of bladder cancer, then to analyze factors influencing overall survival.

\section{Methods}

It is a retrospective study from January 2010 to December 2014 at Fattouma Bourguiba University Hospital of Monastir (Tunisia), an 858-bed tertiary-level teaching hospital with 27 hospital departments, including emergency and outpatient services. All patients with locally advanced and metastatic bladder cancer (stage III or IV) treated in the department of medical oncology were included. Patients who didn't receive any chemotherapy or who were followed-up for less than 24 months were excluded. We identified 40 eligible cases.

The measuring instrument is a grid of observation specially designed for our study and which has been completed by the researcher investigator. Capture and analysis of the data has been made by the SPSS software $20.0 \mathrm{~V}$. Data were expressed in terms of frequencies, percentages, means and standard deviations.

We used Pearson's Chi square test for the comparison of qualitative variables (when application conditions were not satisfied we used correct test of Yates or Fisher exact test) and the T-Student's test for the comparison of quantitative variables. Significance level has been adapted to 0.05 .

Our study obtained a statement that ethics approval was not required.

\section{Results}

During 5 years from January 2010, 293 patients were hospitalized in urology department at University Hospital Fattouma Bourguiba of Monastir (Tunisia) for bladder cancer, among them 40 cases (13.65\%) had locally advanced and/or metastatic forms. Twenty-seven patients $(9.22 \%)$ had locally advanced tumor and 13 patients $(4.43 \%)$ had a metastatic disease.

\section{1) Patients and tumor characteristics:}

At diagnosis, all bladder cancer patients' mean age was $61.9 \pm 10.5$ years with extremes ranging from 33 to 79 years, while mean age of patients with locally advanced and/or metastatic stage was $63.3 \pm 9.6$ years. We also noted a male predominance (37 men and 3 women) with a sex ratio equal to 12.3 . 
In our series, family history of bladder cancer was noted in one patient $(2.5 \%)$, 6 patients had a professional exposure to chemical products (15\%), 35 patients (87.5\%) were smokers, and 15 patients (37.5\%) were initially treated with BCG-therapy for superficial tumors.

Table 1 shows the distribution of patients according to the histological type. The most common one: was transitional cell carcinoma $82.5 \%$. Majority of our patients had a Grade III tumor (95\%). In lymphadenectomy, lymph nodes' mean number was 11.7 (extremes ranging from 2 to 26) with documented invasion in 8 patients (20\%). The number of invaded lymph nodes varied from 1 to 5 .

Table 2 summarizes patients according to TNM classification with 27 patients (67.5\%) having locally advanced tumor and 13 patients (23.5\%) diagnosed with a metastatic disease, most in bone (15\%) and lung (12.5\%) or both (12.5\%).

\section{2) Treatment Modalities}

Surgery was performed in 14 patients (35\%) all of them had radical cystoprostatectomy. Urinary derivation Bricker procedure (use of a segment of the ileum for the diversion of urinary flow from the ureters) was reported in $12 \mathrm{pa}$ tients.

Chemotherapy was performed in 24 patients (60\%). Adjuvant chemotherapy protocol was used for 10 patients (25\%) and was based on 4 courses of gemcitabine-cisplatin. Varied toxicity grades II and III were observed with predominance of vomiting and peripheral neuropathy. There was no renal toxicity. Mean number of neoadjuvant and first-line palliative chemotherapy courses was 3.6

Table 1. Repartition of patients according to histological type.

\begin{tabular}{ccc}
\hline Histological types & Number & Percentage\% \\
\hline Transitional cell carcinoma & 33 & 82.5 \\
Squamous cell carcinoma & 3 & 7.5 \\
Adenocarcinoma & 2 & 5 \\
Sarcomatoid carcinoma & 1 & 2.5 \\
Indifferenciated carcinoma & 1 & 2.5 \\
\hline
\end{tabular}

Table 2. TNM classification.

\begin{tabular}{cccc}
\hline \multicolumn{2}{c}{ Classification } & Number & Percentage \\
\hline \multirow{3}{*}{ T } & T1 & 2 & 5 \\
& T2 & 3 & 7.5 \\
& T3 & 26 & 65 \\
& T4 & 9 & 22.5 \\
N & N0 & 28 & 70 \\
& N1 & 5 & 12.5 \\
& N2 & 7 & 17.5 \\
M & M0 & 27 & 67.5 \\
& M1 & 13 & 32.5 \\
\hline
\end{tabular}


(extremes ranging from 1 to 7 ) and were also based on association of cisplatin with gemcitabine with same toxicity profile. Two patients received second-line chemotherapy based on navelbinemonotherapy, then progression was noticed after two courses. Radiation therapy was indicated in 14 patients of our series (curative in 6 cases, palliative in 8 cases). And 11 patients (27.5\%) had no specific treatment.

\section{3) Follow-Up}

At the last follow-up, 28 patients were died and 12 have survived. Mortality rate was $70 \%$ and mean of overall survival was 14.4 months with extremes of 1 and 50 months. Median overall survival was 12.5 months and overall survival rate was $50 \%$ at 1 year and $10.7 \%$ at 2 years (Figure 1).

Overall survival influencing factors were: general condition (ECOG score) $\mathrm{T}$ and $\mathrm{M}$ tumor stages, primary tumor surgery and chemotherapy (Table 3 and Figures 2-7).

Mean of recurrence-free survival was 7.3 months with extremes of 1 and 20 months and median of recurrence-free survival was 5 months (Figure 8). The rate of recurrence-free survival at 1 year was $16.7 \%$. No factor was correlated with an improvement in recurrence-free survival.

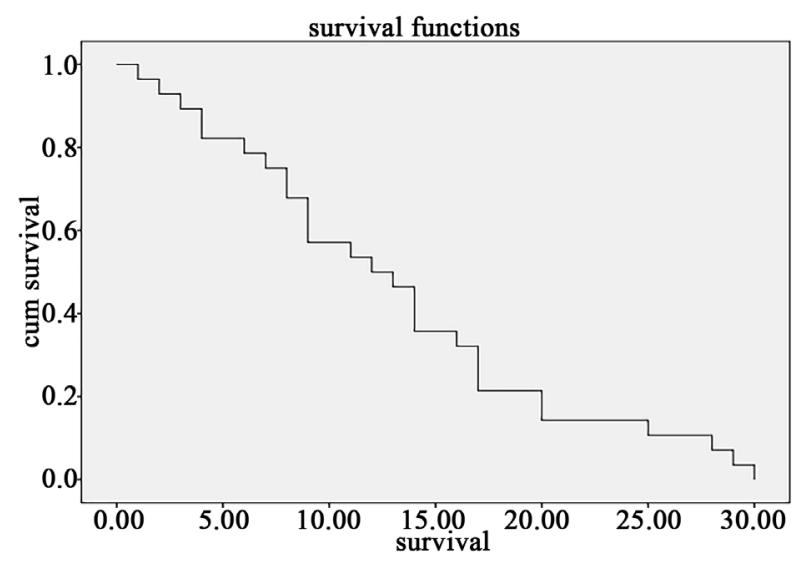

Figure 1. Overall survival curve (months).

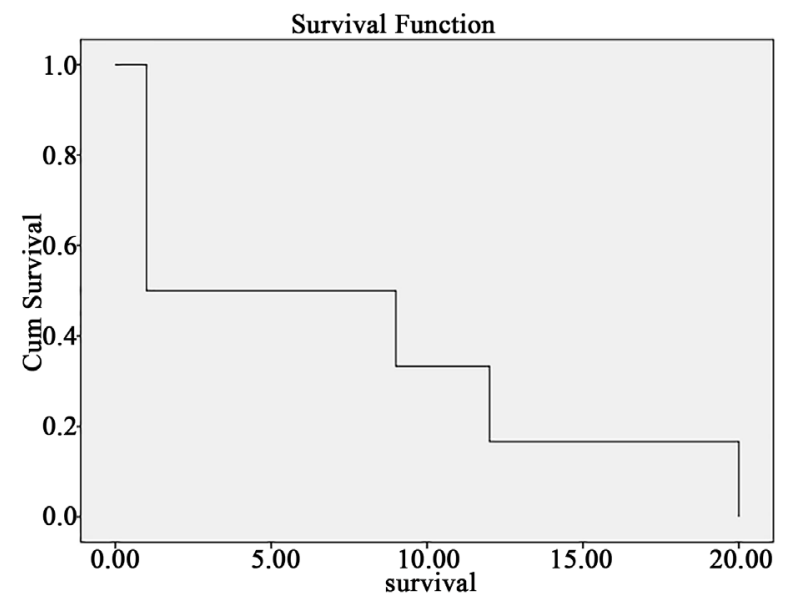

Figure 2. Chemotherapy impact on overall survival (months). 


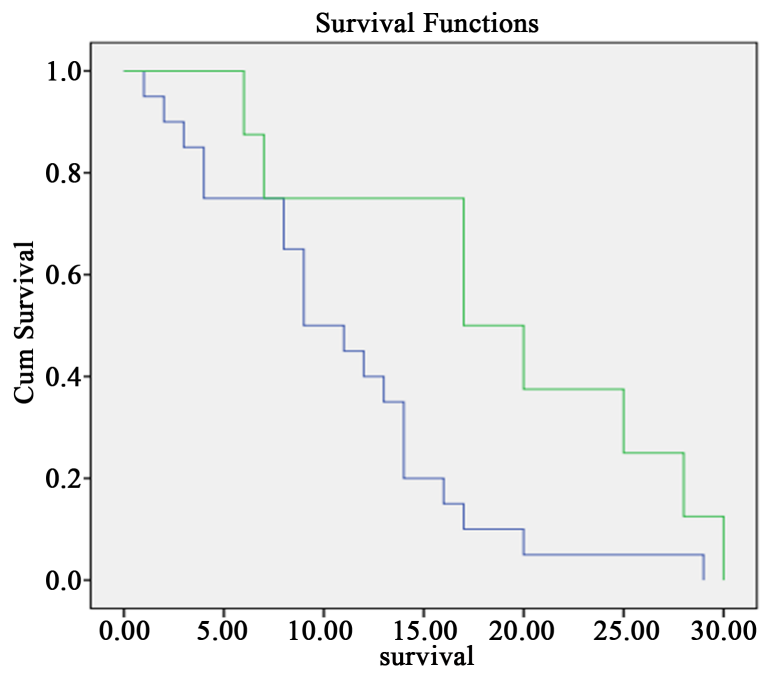

Figure 3. Primarytumorsurgery impact on overall survival (months).

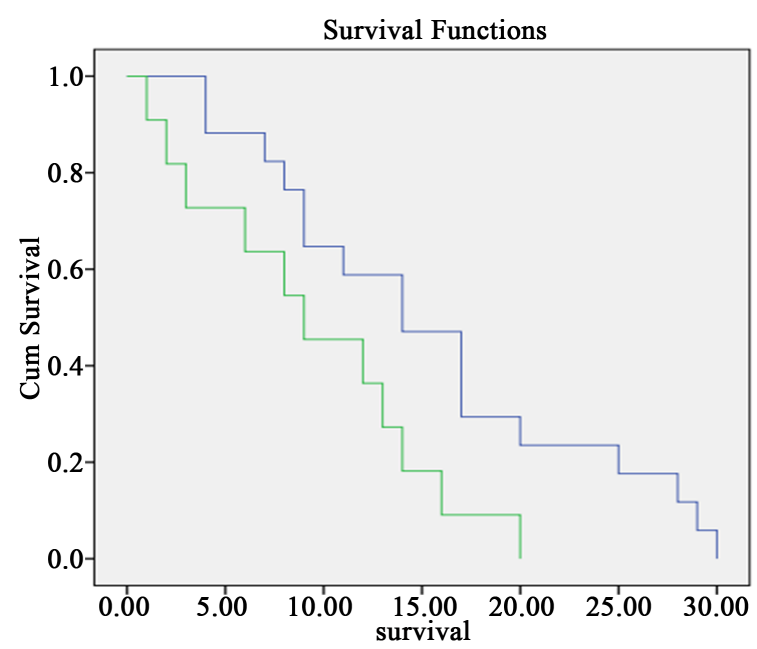

Figure 4. Metastatic profil impact on overall survival (months).

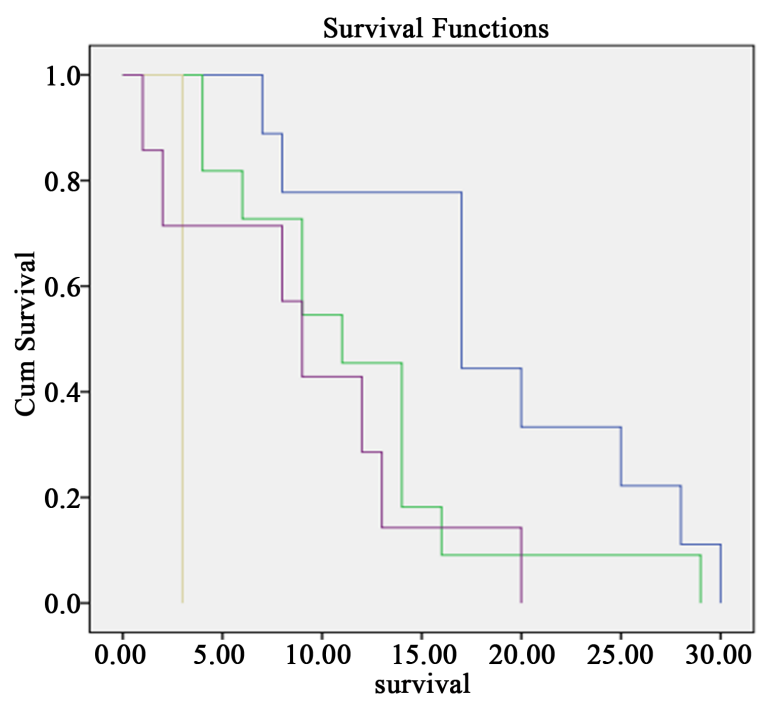

Figure 5. General condition (WH0) impact on overall survival (months). 


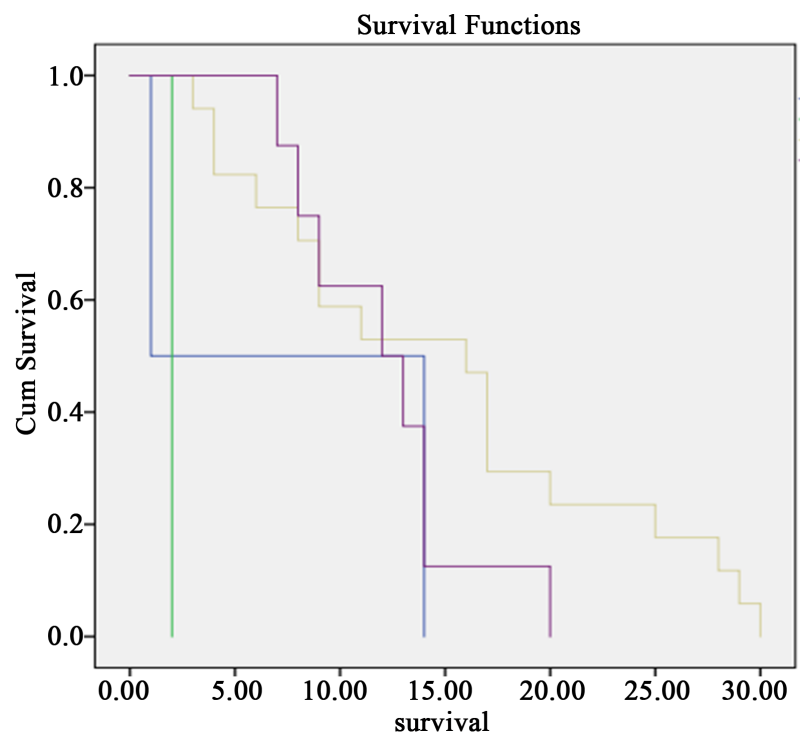

Figure 6. Stagetumor T impact on overall survival (months).

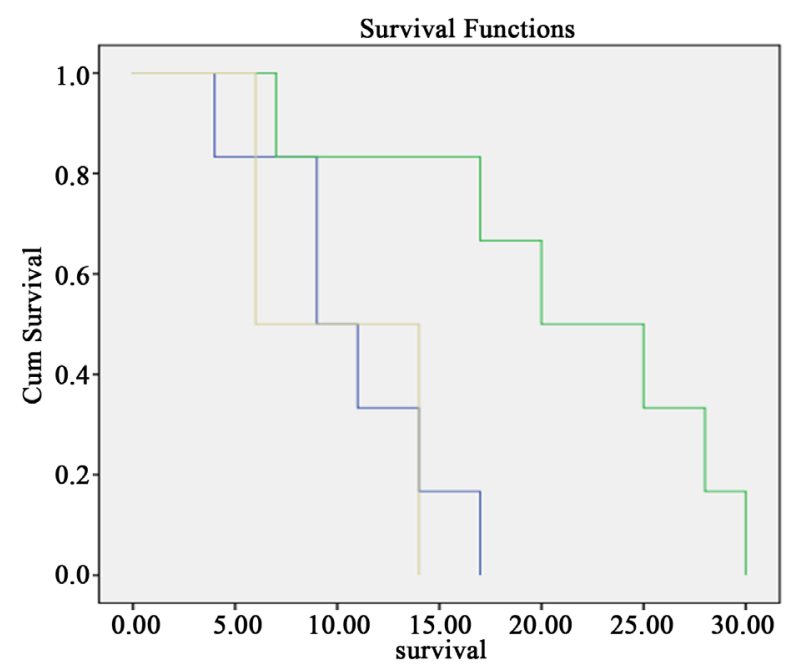

Figure 7. Indication of chemotherapy impact on overall survival (months).

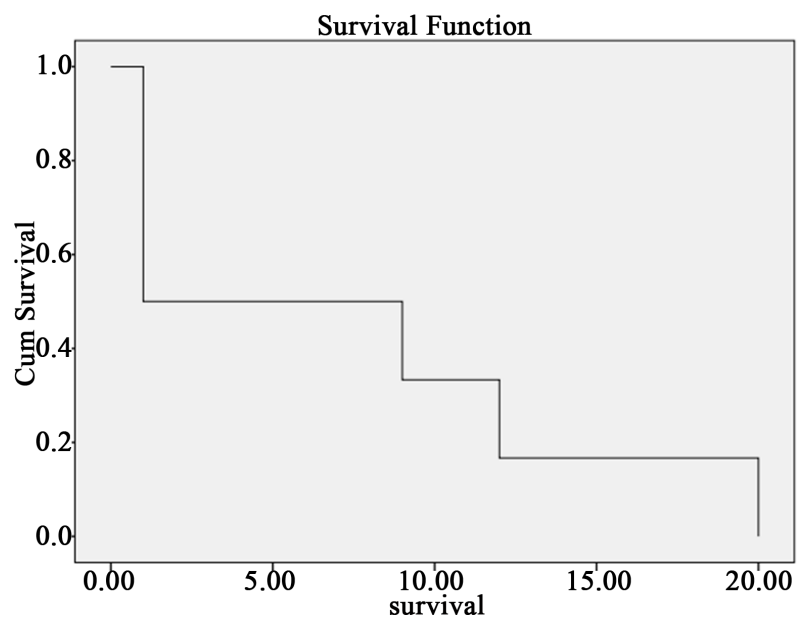

Figure 8. Recurrence-free survival (months). 
Table 3. Prognosis factors of overall survival.

\begin{tabular}{|c|c|c|c|c|c|c|}
\hline Characteristics & Number & $\begin{array}{l}\text { Mean overall } \\
\text { survival } \\
\text { (months) }\end{array}$ & $\begin{array}{c}\text { Confidence } \\
\text { interval 95\% }\end{array}$ & $\begin{array}{c}\text { Median } \\
\text { overall } \\
\text { survival } \\
\text { (months) }\end{array}$ & $\begin{array}{l}\text { Confidence } \\
\text { interval } 95 \%\end{array}$ & $p$ value \\
\hline \multicolumn{7}{|c|}{ Age } \\
\hline$<60$ years & 11 & $16.5 \pm 2.5$ & $11.53-21.55$ & $17 \pm 4.2$ & $8.66-25.33$ & \multirow[t]{2}{*}{0.08} \\
\hline \multirow[t]{2}{*}{$>60$ years } & 17 & $10.9 \pm 1.8$ & $7.41-14.35$ & $11 \pm 2.74$ & $5.62-16.37$ & \\
\hline & \multicolumn{5}{|c|}{ Gender } & \multirow{3}{*}{0.09} \\
\hline Women & 2 & $22 \pm 8$ & $6.32-37.68$ & 14 & - & \\
\hline \multirow[t]{2}{*}{ Men } & 28 & $12.4 \pm 1.5$ & $9.45-15.38$ & $11 \pm 2.1$ & $6.83 \pm 15.16$ & \\
\hline & \multicolumn{4}{|c|}{ Smokers } & & \multirow{3}{*}{0.09} \\
\hline No & 3 & $20.3 \pm 4.9$ & $10.60-29.95$ & $17 \pm 2.4$ & $12.19-21.80$ & \\
\hline \multirow[t]{2}{*}{ Yes } & 25 & $12.2 \pm 1.6$ & $9.17-15.30$ & $11 \pm 2$ & $7.08-14.91$ & \\
\hline & General & condition (W & ld Health Org & ization) & & \multirow{5}{*}{0.004} \\
\hline 0 & 9 & $18.8 \pm 2.7$ & $13.53-24.02$ & $17 \pm 4.5$ & $8.23-25.76$ & \\
\hline 1 & 11 & $11.8 \pm 2.1$ & $7.64-15.99$ & $11 \pm 2.2$ & $6.68-15.31$ & \\
\hline 2 & 1 & 3 & - & 3 & - & \\
\hline \multirow[t]{2}{*}{3} & 7 & $9.3 \pm 2.5$ & $4.41-14.15$ & $9 \pm 1.3$ & $6.34-11.56$ & \\
\hline & & Creatini & Clearance & & & \multirow{3}{*}{0.70} \\
\hline$<60$ & 18 & $13.2 \pm 1.9$ & $9.4-16.9$ & $13 \pm 1$ & $1.1-10.9$ & \\
\hline \multirow[t]{2}{*}{$>60$} & 10 & $13 \pm 2.6$ & $7.8-18.2$ & $9 \pm 1$ & $1-6.9$ & \\
\hline & & TNM s & ging $(T)$ & & & \multirow{5}{*}{0.002} \\
\hline $\mathrm{T} 1$ & 2 & $7.5 \pm 6.5$ & $0-20.24$ & 1 & & \\
\hline $\mathrm{T} 2$ & 1 & 2 & 2 & 2 & & \\
\hline T3 & 17 & $21.1 \pm 1.5$ & $10.54-19.2$ & $16 \pm 3.3$ & $9.5-22.45$ & \\
\hline \multirow[t]{2}{*}{$\mathrm{T} 4$} & 8 & $14.9 \pm 2.2$ & $9.22-15$ & $12 \pm 2.8$ & $6.4-17.54$ & \\
\hline & & TNM s & ging $(\mathrm{N})$ & & & \multirow{4}{*}{0.20} \\
\hline No & 20 & $14.1 \pm 2$ & $10.1-18.1$ & $12 \pm 2$ & $7.6-16.4$ & \\
\hline N1 & 3 & $8 \pm 1$ & $6-9.96$ & 9 & - & \\
\hline \multirow[t]{2}{*}{$\mathrm{N} 2$} & 5 & $12.2 \pm 2.3$ & $7.6-16.77$ & $14 \pm 3.3$ & $7.6-20.4$ & \\
\hline & & TNM s & ging (M) & & & \multirow{3}{*}{0.03} \\
\hline Mo & 17 & $15.5 \pm 2.1$ & $11.40-19.53$ & $14 \pm 2.5$ & $9.16-18.84$ & \\
\hline \multirow[t]{2}{*}{ M1 } & 11 & $9.5 \pm 1.8$ & $5.82-13.08$ & $9 \pm 3.3$ & $2.52-15.47$ & \\
\hline & & Surgery & the tumor & & & \multirow{3}{*}{0.029} \\
\hline No & 20 & $10.8 \pm 1.5$ & $7.88-13.81$ & $9 \pm 1.7$ & $5.71-12.23$ & \\
\hline \multirow[t]{2}{*}{ Yes } & 8 & $18.7 \pm 3.2$ & $12.55-24.94$ & $17 \pm 6.1$ & $4.98-29.01$ & \\
\hline & & Chem & therapy & & & \multirow{3}{*}{0.22} \\
\hline No & 14 & $11.1 \pm 2.1$ & $7.04-15.24$ & $9 \pm 3.7$ & $1.66-16.33$ & \\
\hline \multirow[t]{2}{*}{ Yes } & 14 & $15.1 \pm 2.2$ & $10.75-19.38$ & $14 \pm 2.8$ & $8.55-19.44$ & \\
\hline & & type of $\mathrm{C}$ & motherapy & & & \multirow{4}{*}{0.03} \\
\hline Neoadjuvant & 6 & $10.7 \pm 1.8$ & $7.0-14.2$ & $9 \pm 2.8$ & $3.4-14.6$ & \\
\hline Adjuvant & 6 & $21.2 \pm 3.4$ & $14.4-27.9$ & $20 \pm 4.9$ & $10.39-29.6$ & \\
\hline Palliative & 2 & $10 \pm 4$ & $2.1-17.8$ & 6 & - & \\
\hline
\end{tabular}




\section{Discussion}

In our series, at diagnosis' mean ages were 61.9 years for any stage bladder cancer and 63.3 years for locally advanced or metastatic form. The frequency peak was during the $6^{\text {th }}$ decade. Mean age at diagnosis was 60 to 68 years for men and 71 years for women [5] [6]. In Tunisia, bladder cancer patients' mean age was 65.7 years according to the Serhal series [7], 65.5 years in the Aouni series [8], 64.2 years for the Lazrak series [9], and 62.5 years in the series of Megdiche [10].

Bladder cancer is more common in men than in women with a sex ratio of 5.1

[5] [6] [11]. In our series, $92.5 \%$ of patients were males. Women are generally less likely to develop bladder cancer compared to men, but once they acquire this disease, they have a less favorable prognosis [12]. It has been hypothesized that women have more advanced stages than men due to late diagnosis in women. Symptoms are often attributed to a benign disease [13].

The bladder exposed to all the substances present in the urine. Thus carcinogens and their metabolites excreted by the kidney can act directly on the bladder mucosa. Smoking is the most important risk factor in bladder tumors [11]. It is estimated that $30 \%-50 \%$ of bladder tumors are related to tobacco. It is active cigarette smoking (20 to 30 years) but also passive smoking [14] [15] [16]. In our series, smoking was found in $87.5 \%$ of patients with an average consumption of 49.2 packets-years. Cigarette incriminated substances would be nitrosamines and $\beta$-2 naphthylamine [14] [15] [16].

Bladder carcinomas are transitional cell carcinomas in $90 \%$ of cases. The other types of urothelial cancer are relatively uncommon, including lymphoepithelioma-like or sarcomatoid carcinomas, micropapillary and primary squamous cell carcinomas and adenocarcinomas [10] [12]. Sometimes the tumor may present a mixed appearance associating urothelial and squamous cell carcinoma or adenocarcinoma. But the most common histological type which accounts for about $90 \%$ of bladder tumors is still urothelial carcinoma. In our series, the most frequent histological types were transitional cell carcinoma in $82.5 \%$ of cases and squamous cell carcinoma in $7.5 \%$ of cases.

Surgical treatment remains actually, the only curative treatment of bladder cancer. Total cystectomy associated extended lymphadenectomy is the standard treatment for muscle-invasive bladder cancer [11] [17]. When the sphincter and the urethra are conserved and functional, bladder replacement is the most comfortable solution. However, in the case of an ureterectomy, this replacement is impossible thus, we need a transcutaneous urinary derivation [11].

Radiotherapy can interfere in different circumstances for bladder cancer: exclusively or in combination with surgery or chemotherapy [17] [18]. When an exclusive radiotherapy is indicated, the dose delivered (bladder and iliac lymph nodes) is 45 Gray (Gy). An additional 20 to $25 \mathrm{~Gy}$ is indicated for inoperable patients, so a total tumor dose of 60 to 70 Gy [19]. Pre-operative radiotherapy: of 45 to $50 \mathrm{~Gy}$ total dose delivered to the pelvis is not indicated according to a study by Smith et al. [20], comparing overall survival in the case of radical cys- 
tectomy with or without preoperative radiotherapy in patients with superficial bladder cancer with high grade and high risk of recurrence or with evidence of bladder muscle invasion; The overall survival at 5 years was evaluated up to $43 \%$ in patients who had a neoadjuvant radiotherapy followed by radical cystectomy and up to $53 \%$ to those who had to radical cystectomy alone $(p=0.23)$. The median overall survival was 2.2 years and 5.3 years, respectively. However, a meta-analysis by Huncharek et al. [21], had compared neoadjuvant radiotherapy followed by radical cystectomy with radical cystectomy alone in the treatment of invasive bladder cancer, and has demonstrated a reduction in the relative risk of 5 -year mortality from $29 \%$ in favor of preoperative radiotherapy and this reduction was not statistically significant.

Several studies have shown chemotherapy's benefits in urothelial tumors in term of response rate and survival [6]. Encouraging results in the metastatic context raised the hypothesis that neoadjuvant and adjuvant chemotherapy may also demonstrate efficacy in patients with invasive bladder cancer. Chemotherapy is generally better tolerated before surgery, so doses and a higher number of cycles can be administered. Objectives of neoadjuvant chemotherapy are to eradicate potential micro-metastases, reduce the size of the tumor, reduce the risk of tumor cells dissemination on surgery and improve survival [22].

The primary therapeutic standard for metastatic bladder cancers from 1989 to 2000 was the "MVAC" protocols with a complete response of $72 \%$. The median survival was 12 - 15 months and 7\% were long survivors [23] [24]. A new standard in 2000 was the Gemcitabine-Cisplatin protocol where the European phase III trial of Vander Maase showed its identical efficacy to the MVAC protocol in terms of objective response ( $46 \%$ versus $49 \%$ ) and survival at 5 years , $3 \%$ versus 13\%) but with less toxicity [25]. The Phase III EORTC trial published in 2006 compared the effect of the intensified MVAC protocol with the standard MVAC protocol used also in the first metastatic line in bladder cancer and the results showed identical effect in terms of objective response $50 \%$ Versus $62 \%$ and median progression-free survival ( 9 months versus 8 months) with lower toxicity due to the combination with growth factors [26].

Regarding second-line chemotherapy, the Maha study published at ASCO (American Society of Clinical Oncology) in 2008 reported the main drugs in the second line [27]. Table 4 summarizes the objective response and median survival of the different protocols of chemotherapy.

Table 4. Results of second line chemotherapy [27].

\begin{tabular}{ccc}
\hline & Objective response (\%) & Median of survival (month) \\
\hline Pemetrexed & $27 \%$ & $9.6 \%$ \\
Docetaxel & $13 \%$ & $9 \%$ \\
Paclitaxel & $10 \%$ & $7 \%$ \\
Ifosfamide & $5 \%-20 \%$ & $5.5 \%$ \\
Gemcitabine & $11 \%-23 \%$ & $5.8 \%$ \\
Vinfluvine & $9 \%$ & $6.9 \%$ \\
\hline
\end{tabular}


The improvement of the understanding of the molecular biology of bladder tumors made possible determination of the different signaling pathways involved in both carcinogenesis and tumor progression. In these pathways, some molecules serve both as prognostic markers and as potential therapeutic targets. Locally advanced and/or metastatic bladder cancer is characterized by alterations in the cell cycle regulating p53 and $\mathrm{Rb}$ genes that interact with the transduction pathway (MPAK). Overexpression of tyrosine kinase receptors, including EGFR, VEFGR and HER2/neu, is correlated with tumor progression, pathway activation (PI-3K) and tumor invasion. The molecular heterogeneity of bladder tumors requires the combination of several molecules allowing an optimal treatment. Moreover, the modulation of signaling pathways by these new molecules makes it possible to restore a chemo sensibility to the cytotoxic drugs which can then be associated with the targeted treatments [28].

Different prognostic factors are currently proposed in order to define different risk groups, thus guiding in the management of bladder tumors

\section{O General prognostic factors [10] [12]}

The alteration of the general condition;

The existence of associated pathologies: cardiorespiratory and hematopoietic;

The persistence of exposure to one of the risk factors that lead to recurrence;

The advanced age of the patient beyond 70 years, although infiltrating tumors in the young (less than 40 years) are particularly aggressive, with a very rapid potential of evolution.

Sex is not correlated with prognosis.

\section{$O$ Prognostic factors related to the tumor}

\section{Aspect of the tumor.}

The macroscopic aspect of the tumor: Papillary tumors have a better prognosis than solid tumors (sessile or nodular). This correlation is probably partly related to grade, since solid tumors are in $70 \%$ of grade III cases [29]. The pejorative prognostic importance of the tumor's solid character is confirmed in terms of survival.

\section{Size of the tumor.}

The smaller the tumor (less than $2 \mathrm{~cm}$ ), the lower the risk of recurrence and progression is. A tumor diameter greater than or equal to $5 \mathrm{~cm}$ is associated with a poor prognosis due to a more frequent association with distant metastatic dissemination [29].

\section{Location of the tumor.}

The risk of recurrence and progression are lower when the tumor focus is unique than when there are several associated foci [29]. Multifocality is explained by the instability of the urinary urothelium and it obliges the urologist to perform a series of randomized biopsies on apparently healthy mucosa during cystoscopy.

The recurrence rate for superficial tumors before adjuvant therapy significantly affects the future rate of recurrence and progression; the interval between the recurrences tends to decrease with time. Tumor progression is observed in 
$20 \%$ to $25 \%$ of primitive superficial tumors, while $56 \%$ of recurrences progress [30].

Bladder neck localization is poor prognosis (39\% survival at 5 years versus $50 \%-56 \%$ for others).

The renal function state and the repercussion of the tumor on the upper urinary tract with ureterohydronphrosis have a pejorative value [31].

\section{Stage of the tumor:}

The aggravation of the tumor stage is of pejorative prognostic significance.

Survival is correlated with the stage of the tumor. The prognosis is more pejorative in terms of survival as the degree of tumor infiltration is deep. It is associated with vasculo-lymphatic infiltration and/or metastatic dissemination. However, even in cases of lymph node invasion, the main survival factor remains the pathological stage. In the case of lymph node invasion, the survival expectation is $119 \pm 68.8$ months if the primary tumor is less than pT3a compared to $15.7 \pm 2.6$ months if the primary tumor is higher than pT3a [29].

\section{Cell Grade :}

It is an important prognostic factor of survival for infiltrative bladder tumors. High-grade tumors have a higher rate of recurrence, progression and death. (36\% recurrence for grade I versus $70 \%$ for grade II) [30].

\section{Histological type:}

The histological type has its importance, since the epidermoid tumors have a more pejorative prognosis [12].

\section{Response to chemotherapy.}

There is correlation between survival and administration of neoadjuvant chemotherapy. A 5-year survival rate of $75 \%$ has been reported in the literature for tumors that have become pT0, compared to $20 \%$ for those that remain infiltrative [30].

\section{Biological prognostic factors:}

\section{The ploidy:}

The determination of the cells' DNA content by flow cytometry represents superior information to the histological determination of the tumor grade only for grade II. We distinguish biologically aggressive aneuploid tumors and diploid or tetraploid tumors with better prognosis [29].

\section{Chromosomal abnormalities:}

Tumor suppressor gene p53 was identified on chromosome 17 . That is why it is thought that deletions or mutations at this level may explain tumorogenesis. Indeed, deletions of chromosome 11 and 17 were identified as poor prognostic elements [30].

The antigenic factors:

- ABO blood group antigens: The study of $\mathrm{ABH}$ blood group antigens showed that loss of expression of these antigens accompanied tumor dedifferentiation and may increase the risk of tumor progression [30].

- Tumor-associated antigens: some tumor-associated antigens have been 
shown to be useful in the prognostic determination of tumors [31].

\section{Growth Factors.}

Growth factors and their receptors: EGF (epidermoid growth factor) is a good indicator of the risk of subsequent invasion of superficial tumors [32].

In our study the factors influencing the overall survival were: general condition (WHO), $\mathrm{T}$ and $\mathrm{M}$ tumor stages, and primary tumor surgery and adjuvant chemotherapy.

\section{Conclusions}

In order to improve the survival and prognosis of bladder tumors, it is important to discuss in a multidisciplinary team the best treatment to be proposed in each case by involving the patient in the therapeutic decision; to integrate the different therapeutic options (surgery, chemotherapy and radiotherapy); to give priority to the most effective and least toxic strategy in the management of these advanced forms; to take into account the prognostic factors proved in the literature; and to include the improvement of the quality of life in the objective of the proposed treatments.

The importance of promoting the early diagnosis of advanced forms and the need to continue primary prevention through tobacco control and reduction of occupational exposure to carcinogens should be emphasized.

\section{References}

[1] Jacons, B.L., Lee, C.T. and Montie, J.E. (2010) Bladder Cancer in 2010: How Far Have We Come? CA: A Cancer Journal for Clinicians, 60, 244-272. https://doi.org/10.3322/caac.20077

[2] Stenzl, A., Witfies, J.A., Cowan, N.C., De Santis, M., Lebret, T., Merseburger, A.S., et al. (2011) Guidelines on Bladder Cancer Muscle Invasive and Metastatic. European Urology, 59, 1009-1018. https://doi.org/10.1016/j.eururo.2011.03.023

[3] Korbi, S., et al. (2001) Registre du cancer du centre tunisien. [Cancer Registry of the Tunisian Center].

[4] Ministry of Public Health, Institute Salah Azaiez, Service of Epidemiology, Biostatistics and Medical Informatics. Register of the Institute Salah Azaiez 1994-1999: 105-107.

[5] Bang, K.M. (1996) Epidemiology of Occupational Cancer. Occupational Medicine, 11, 467-485.

[6] Houede, N., Locker, G., Lucas, C., Soto Parra, H., Basso, U., Spaeth, D., et al. (2016) Epicure: European Epidemiology Study of Patients with an Advanced or Metastatic Urothelial Carcinoma Having Progressed to Platinium-Based Chemotherapy. BMC Cancer, 16, 752. https://doi.org/10.1186/s12885-016-2782-3

[7] Serhal, A. (2010) The Superficial Tumors of the Urinary Bladder PT1G3: Diagnostic, Therapeutic and Prognostic Aspects: About 40 Cases. Medical Thesis Monastir Medicine.

[8] Aouni, A. (2007) Les tumeurs superficielles de la vessie PT1G3: Aspects diagnostiques, thérapeutiques et pronostiques. A propos de 40 cas. [The Superficial Tumors of the Bladder PT1G3: Diagnostic, Therapeutic and Prognostic Aspects. About 40 Cases]. Thèse Médecine Monastir. 
[9] Lazrak, N. (2012) Bladder Tumors pTa: Factors of Recurrence and Progression. Medical Thesis Monastir Medicine.

[10] Zeghidi Megdiche, M.H. (2012) Epidermoid Carcinoma of the Bladder: About 20 Cases. Thesis Monastir Medicine.

[11] Witjes, J.A., Lebret, T., Compérat, E.M., Cowan, N.C., De Santis, M., Bruins, H.M., et al. (2016) Updated 2016 EAU Guidelines on Muscle-Invasive and Metastatic Bladder Cancer. European Urology, 71, 462-475.

[12] Pfister, C., Roupret, M., Wallerand, H., Davin, J.L., Straights, H., Guy, et al. (2013) Recommendations in Urology. Progrès en Urologie, No. 2, S105-S125.

[13] Chopin, D., Vordos, D. and Gattegno, B. (2001) Superficial Tumors of the Bladder: Etiologies. Progress in Urology, 11, 825-952.

[14] Bjerregaard, B.K., Raaschou-Nielson, O., Sorensen, M. and Frederiksen, K. (2006) Tobacco Smoke and Bladder Cancer in the European Prospective Investigation into Cancer and Nutrition. International Journal of Cancer, 119, 412-416. https://doi.org/10.1002/ijc.22169

[15] Brennan, P., Bogillot, O., Cordier, S., Greiser, E. and Schill, W. (2000) Cigarette Smoking and Cancer of the Bladder in Men: A Pooled Analysis of 11 Case-Control Studies. International Journal of Cancer, 82, 289-294.

https://doi.org/10.1002/(SICI)1097-0215(20000415)86:2<289::AID-IJC21>3.0.CO;2$\underline{\mathrm{M}}$

[16] Gandini, S., Botteri, E., Iodice, S., Boniol, M., Lowenfels, A.B., Maisonneuve, P. and Boyle, P. (2008) Smoking and Cancer: A Meta-Analysis. International Journal of Cancer, 122, 155-164. https://doi.org/10.1002/ijc.23033

[17] Riou, O., Chauvet, B., Lagrange, J.L., Martin, P., Moscardo, C.L., Charissoux, M., et al. (2016) Radiotherapy of Cancers of the Bladder. Cancer Radiother.

[18] Shipley, W.U., Winter, K.A., Kaufman, D.S., Lee, W.R., Heney, N.M., Tester, W.R., et al. (1998) Phase III Trial of Neoadjuvant Chemotherapy in Patients with Invasive Bladder Cancer Treated with Selective Bladder Preservation by Combined Radiation Therapy and Chemotherapy Initial Results of Radiation Therapy Oncology Group 89-03. Journal of Clinical Oncology, 16, 3576-3583. https://doi.org/10.1200/JCO.1998.16.11.3576

[19] Cowan, R.A., Mc Bain, C.A., Ryder, W.D., et al. (2004) Radiotheraoy for Muscle Invasive Carcinoma of the Bladder: Results of a Randomized Trial Comparing Conventional Whole Bladder with Dose-Escalated Partial Bladder Radiotherapy. International Journal of Radiation Oncology Biology Physics, 59, 197-207.

[20] Smith, J.A., Crawford, E.D., Paradelo, J.C., Blumenstein, B., Herschman, B.R., Grossman, H.B., et al. (1997) Treatment of Advanced Bladder Cancer with Combined Preoperative Irradiation and Radical Cystectomy versus Radical Cystectomy Alone: A Phase III Intergroup Study. Journal of Urology, 157, 805-807.

[21] Huncharek, M., Muscat, J. and Geschwind, J.F. (1998) Planned Preoperative Radiation Therapy in Muscle Invasive Bladder Cancer: Results of a Meta-Analysis. Anticancer Research, 18, 1931-1934.

[22] Sherif, A., Holmberg, L., Rintala, E., Mestad, O., Nilsson, O., Nilsson, J., et al. (2004) Neoadjuvantcisplatinium Based Combination Chemotherapy in Patients with Invasive Bladder Cancer: A Combined Analysis of Two Nordic Studies. European Urology, 45, 297-303.

[23] Sternberg, C.N., Donat, S.M., Bellmunt, J., Millikan, R.E., Stadler, W., De Mulder, P., et al. (2007) Chemotherapy for Bladder Cancer: Treatment Guidelines for 
Neoadjuvant Chemotherapy, Bladder Preservation, Adjuvant Chemotherapy, and Metastatic Cancer. Urology, 69, 62-79.

[24] Sternberg, C.N., Yagoda, A., Scher, H.I., Watson, R.C., et al. (1989) Methotrexate, Vinblastine, Doxorubicin and Cisplatin for Advanced Transitional Cell Carcinoma of the Urothelium. Efficacy and Patterns of Response and Relapse. Cancer, 64, 2448-2458.

https://doi.org/10.1002/1097-0142(19891215)64:12<2448::AID-CNCR2820641209> 3.0.CO;2-7

[25] Von der Maase, H., Hansen, S.W. and Roberts, J.T. (2000) Gemcitabine and Cisplatine (GC) versus Methotrexate, Vinblastine Adriamycin and Cisplatin (MVAC) Chemotherapy in Advanced or Metastatic Transitional Cell Carcinoma (TCC) of the Urothelium: A Large Randomized Multicenter, Multinational Phase III Study. American Society of Clinical Oncology, 19, 329.

[26] Sternberg, C.N., de Mulder, P., Schornagel, J.H., Theodore, C., Fossa, S.D., van Oosterom, A.T., et al. (2006) Seven Year Update of an EORTC Phase III Trial of High-Dose Intensity M-VAC Chemotherapy and G-CSF versus Classic M-VAC in Advanced Urothelial Tract Tumours. European Journal of Cancer, 42, 50-54.

[27] Maha, H., Hussain, A., Wood, D.P., et al. (2009) Bladder Cancer: Narrowing the Gap between Evidence and Practice. Journal of Clinical Oncology, 27, 5680-5684.

[28] Wallerand, H., Robert, G., Bernhard, J.C., et al. (2008) Targeted Therapy for Localy Advanced and/or Metastatic Bladder Cancer. Progrès en Urologie, 18, 407-417.

[29] Coulange C. Prognostic Factors of Tumors of Bladder. Rev Prat 1997.

[30] Cussenot, O. and Ravery, V. (1995) Classifications and Prognostic Factors of Epithelial Tumors of the Bladder. EMC (Paris-France), Néphrologie-Urologie, 18-243-A-20, 5 p.

[31] Kaufman, D.S., Shilpey, W.U. and Griffin, P.P. (1993) Selective Bladder Preservation by Combined Modality Treatment of Invasive Bladder Cancer. The New England Journal of Medicine, 329, 1377-1381. https://doi.org/10.1056/NEJM199311043291903

[32] Wityes, J.A., Umbas, R., Debrayne, F.M. and Schalnen, J.A. (1995) Expression of Markers for Transitional Cell Carcinoma in Bladder Mucosa of Patients with Bladder Cancer. Journal of Urology, 154, 218-219. 
Submit or recommend next manuscript to OALib Journal and we will provide best service for you:

- Publication frequency: Monthly

- 9 subject areas of science, technology and medicine

- Fair and rigorous peer-review system

- Fast publication process

- Article promotion in various social networking sites (LinkedIn, Facebook, Twitter, etc.)

- Maximum dissemination of your research work

Submit Your Paper Online: Click Here to Submit

Or Contact service@oalib.com 